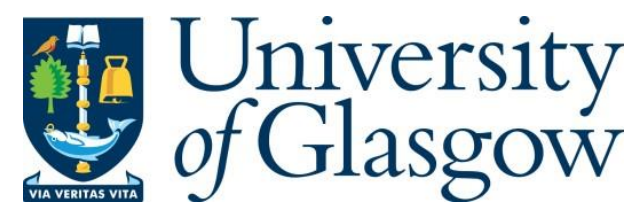

Acharya, S., Bryant, L. and Twiddy, M. (2017) Altruism or obligation? The motivations and experience of women who donate oocytes to known recipients in assisted conception treatment: an interpretative phenomenological analysis study. Journal of Psychosomatic Obstetrics and Gynecology, 38(1), pp. 4-11.

There may be differences between this version and the published version. You are advised to consult the publisher's version if you wish to cite from it.

http://eprints.gla.ac.uk/214534/

Deposited on: 30 June 2020

Enlighten - Research publications by members of the University of Glasgow http://eprints.gla.ac.uk 


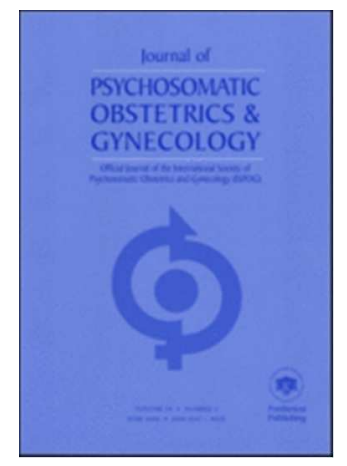

Altruism or obligation? The motivations and experience of women who donate oocytes to known recipients in assisted conception treatment: An Interpretative Phenomenological Analysis study

\begin{tabular}{|r|l|}
\hline Journal: & Journal of Psychosomatic Obstetrics \& Gynecology \\
\hline Manuscript ID & DPOG-2015-0131.R2 \\
\hline Manuscript Type: & Original Research \\
\hline Keywords: & $\begin{array}{l}\text { oocyte donation, motivation, experience, interpretative phenomenological } \\
\text { analysis, qualitative methods }\end{array}$ \\
\hline \multicolumn{2}{|c}{} \\
\hline
\end{tabular}




\title{
Altruism or obligation? The motivations and experience of women who donate oocytes to known recipients in assisted conception treatment: An Interpretative Phenomenological Analysis study
}

\begin{abstract}
:
Introduction: This qualitative study was conducted to explore the motivations and experience of oocyte donors donating to women known to them. Methods: Three women who donated oocytes to a close relative were interviewed and data analysed using an Interpretative Phenomenological Analysis approach. Results: The two key elements noted were 'motivations for donation' and 'coping with the consequences of oocyte donation'. The motivation for donation was influenced by the familial bond that was strengthened by the donation process in some cases. The concept of altruistic oocyte donation stemmed from the narratives of giving the gift of motherhood and gaining a positive self-image and respect from others. Coping with the consequences of oocyte donation tests the donor identity, their wishes for a positive outcome, concerns regarding disclosure of biological motherhood and detachment from the egg and potential child. Discussion: Motivation is influenced by a combination of factors including the rewards of altruistic behaviour, the existence and potential strengthening of the relationship between donor and recipient, but possibly also, a sense of obligation and societal expectations. Oocyte donation can be variously viewed by donors as a unique way of reproductive empowerment or an example of acceding to subtle coercion and thus disempowerment. The study also highlights the clinical as well as ethical importance of providing support services for oocyte donors and recipients.
\end{abstract}

\section{Introduction:}


Oocyte donation is an established procedure for women to achieve a pregnancy via assisted reproductive technology (ART). Data from the USA show donor eggs or embryos were used in approximately $11 \%$ of the 190,773 ART cycles performed [1]. Oocyte donation is an intrusive and complex process and has the potential for significant psychological, physical and social impacts on donor and recipient [2, 3].

The Human Fertilisation and Embryology (HFEA) Act, UK, 2005 [4] lifted anonymity from oocyte donors and allows donor conceived children to access the identity of their donor when they reach the age of 16 . In spite of concerns that this would lead to a reduction in the number of women volunteering to donate oocytes, the first HFEA report on gamete donation in 2014 showed there was an increase in oocyte donation since 2006, although the demand still far outstrips supply [5].

Sister-to-sister donation has been advocated because of the assumption that a common genetic heritage may allow recipient parents to bond better with their child [6]. In support of this, a review reported positive attitudes of infertile couples towards oocyte donation by sisters [7].The limited literature suggests that oocyte donation between two people known to each other has mainly altruistic motives, and donors are motivated to donate to a family member because of their personal relationship [8-11]. Others have further identified that an empathic understanding of the emotional pain of infertility is part of this motivation [12-15]. However, it has also been argued that because society expects women to be caring and family centred, refusing a donation request from a family member may be difficult [16]. 
Despite the importance of understanding the motivations and experiences of women who donate oocytes there is a paucity of in-depth research exploring the donors', rather than the recipients' perspective [17]. This study aimed to address this gap using a qualitative interpretative phenomenological analysis (IPA) approach [18]. IPA is used to explore the processes through which participants make sense of their own experiences, by examining the respondent's accounts of the phenomena under consideration [19].

\section{Methods:}

\section{Recruitment}

Sampling was purposive. Twelve women who had donated oocytes to a known recipient in the previous five years at one NHS hospital in England were invited to take part by letter. None had received any financial reward for donation. SA was a male clinician in the department where the women attended for treatment. None were previously known to SA and he was not involved in their care. Of the six responders, four initially expressed willingness to participate in the research. Of these four, three finally took part. The reasons for non-response or declining to participate are unknown since no further contact was made after the initial invitation. One woman withdrew consent prior to interview without giving a reason and this was respected without further contact being made.

\section{Summary of the participants}

All three participants were Christian, British Caucasian women who had genetic children of their own. All were biologically related to the recipient. Participants 
therefore constituted a homogenous sample. To maintain confidentiality, donoridentifying information has been excluded with pseudonyms used throughout.

Anne (30 years) and Debbie (35 years) identified as housewives, each 'happily married' to the father of their two children. Both had donated oocytes to their aunts three years previously, with whom they had very close relationship. In both cases their donation did not result in a successful pregnancy. Susan (38 years) worked as a nurse. She was divorced from the father of her two children and identified as a 'single mother'. Susan's donation to her sister two years previously had resulted in a successful pregnancy and she occasionally met her sister's child.

Anne was very open and positive about her decision. She had no plans for a future pregnancy. Debbie was very 'happy' narrating her story, and although she may have liked another child, her circumstances precluded this. Susan appeared to be more reticent about the experience during the interviews. She did not rule out having further children of her own with a future partner.

\section{Procedure}

The interviews were conducted by SA. The participants were informed of the reason for conducting the research, and were aware of SA's credentials before they consented to take part. Interviews were held in a dedicated counselling room on the Assisted Conception Unit and lasted 45-60 minutes. Participants consented to the interviews being audio recorded and field notes being taken. The topic guide was based around motivations to donate, experiences of the donation and reflections on this experience.

Data Analysis 
The interviews were transcribed verbatim and analysed using Interpretative Phenomenological Analysis following the four stage process described by Smith and Osborn [19]: (1) Looking for themes in the first transcript, (2) Connecting themes, (3) Continuing approach with other transcripts, (4) Translating themes to narrative. The reflexive diary kept by SA informed the analysis. The findings reviewed by two experienced qualitative researchers (co-authors) to ensure the interpretations were well grounded within the original data.

Ethical approval

Ethical approval for the study was granted "[detail removed for blind review]"

\section{Results}

Two key elements of the participant narratives were identified: 'Motivations for donation' and 'Coping with the consequences of oocyte donation'. Each of these elements comprised a number of sub-themes.

\section{Motivations for oocyte donation}

The motivation to donate was encompassed within two main themes (1) the familial bond and (2) altruism. Both themes have a number of sub-themes.

\section{(1) The familial bond}

\section{Knowing the potential parents}

Anne and Debbie were willing to go through the invasive process of oocyte donation only for someone they knew well. There was a sense of responsibility regarding the welfare of any potential offspring. 
'I don't think I could do it for a stranger though, I don't know them as a person, they might just have a child and be not very nice people to that child' (Debbie)

Anonymous donation would also deny Debbie the chance to know if a pregnancy ensued and the sense of fulfilment gained from knowing she had helped the couple.

Susan did not rule out anonymous donation, however, she acknowledged that unless she had been asked by her sister she would not have considered donation:

'Could I have done that for somebody else? I probably wouldn't routinely offer my eggs.'

\section{Donation as a means to strengthen the familial bond}

Anne had a strong bond with her aunt, to whom she donated her oocytes.

'She's the closest thing l've got to a mum now... I love her to pieces, so I'll do anything for her.'

Debbie felt that donating to her aunt had brought them closer together.

'That's what motivated me, to know that it is special... I know that they have all the love in the world to give'

The act of donation appeared to be intrinsically rewarding for these two women, who felt that their action would cement existing bonds, evoke kindness and foster generosity. Anne and Debbie described their family as close and that helping someone in their family was a natural thing to do. In contrast, Susan said nothing to suggest that she shared a particularly close relationship with her sister. Instead, she was surprised to be asked since she viewed herself as a less than ideal candidate. ' 
was surprised at [her] choosing me [long pause]. The other two sisters are both doctors [laughs]... they are more intellectual'.

\section{Donation in the context of the wider family}

The participants provided different perspectives on the role other family members had played in their decision making. Anne and Debbie's family and Susan's wider family (siblings and parents) were 'very supportive'. However, Anne and Debbie revealed that oocyte donation had also provoked some familial disharmony.

'I had an argument with my sister-in-law over it; she said the same thing as the counsellor, 'this is not your child [to her aunt]'. (Anne)

'My mother-in-law is a bit old fashioned ... she said you shouldn't mess with nature'. (Debbie)

(2) Altruism

\section{Giving the gift of motherhood}

Participants felt very passionate about the 'right to motherhood' and a strong motivation was to help someone else achieve this 'natural' life progression.

'It was something she really wanted and having my own two children... I

would never be without them [laughs], however hard work they are.' (Susan)

'It's priceless' (Anne)

'Best thing in the world...it's a special thing... in whatever shape or form its offered to you, whether it's natural, not natural' (Debbie). 
When asked whether the experience of donating oocytes has changed them in any way the participants mentioned that they have even contemplated surrogacy for their loved one to achieve a pregnancy.

'Although I do not want more children of my own, I have thought about it, it would be nice to have a girl but you never know what you are going to get... Maybe it is not a need for children of my own because I know we can't really maybe support another child... Maybe it's a need for being pregnant, maybe surrogacy and being able to give somebody that child...' (Debbie)

'I have read about surrogacy, which I did say to my auntie that I would do as well. I would be her oven for nine months, just so she could have something that I have already got' (Anne)

\section{Self-sacrifice}

Anne stopped smoking and lost weight, to be an oocyte donor, which she described as 'life-changing' sacrifices. In spite of being aware of the ill effects of smoking in pregnancy she did not stop in her own pregnancies, but did so 'for her aunt'. The procedure of oocyte donation is invasive and potentially risky but participants were still willing to undertake the procedure to help others.

'I suppose I had some qualms about the procedure itself but put them aside to try and help her' (Susan)

For Debbie and Susan, there were concerns that oocyte donation could be detrimental to their own fertility prospects, should they want to extend their family, although they had no immediate plans to do so. 
I suppose, at the back of my mind there is consideration I might want another one again, at some stage, if I am with someone else... [laughs] I've already given eight eggs away (Susan)

\title{
Gaining a positive self-image and respect from others
}

Donation had provided Anne and Debbie with a positive opportunity to enhance their sense of self-worth as 'givers'.

'I am more of a giving person...I didn't think about it, as soon as she asked me my answer was yes' (Anne).

‘'m a charitable person; I'll give if I can’ (Debbie).

In contrast, Susan appeared to wish to avoid a negative judgement on her 'self'.

'It was something she wanted a great deal so it's not something I could just say, no... It would be selfish for me to say no'.

Oocyte donation made them feel they were respected by family and friends because of the contribution they had made towards their family.

'People still now say 'Oh please tell us about it'... ‘ don't know if I could do that' ... they have a bit of respect' (Debbie)

\section{Coping with the process and consequences of donation}

\section{Wanting a positive outcome}

\begin{abstract}
All donors were not only anxious for a positive outcome for the recipients but also themselves to justify the sacrifices made or effort expended
\end{abstract}


'I think I would just want to know if they ever did get pregnant. Did I help somebody? That sounds terrible but was it for nothing?' (Debbie)

Participants also felt a sense of responsibility to deliver good quality oocytes which could result in a successful pregnancy.

'When it came to the time of harvesting I was more worried about the eggs, are they going to be strong enough, are they the right size, are they everything that they want, is there enough. I was gutted when it did not work.' (Anne)

Potential donors may not be fully aware of the potential for 'failure'. Anne commented on how 'surprised' she was when she came to know of the 'relatively low success rates' of oocyte donation.

\section{Becoming redundant}

During the donation process, the donor briefly becomes the focus of attention in the infertility story. They have intense contact with the clinic with daily medication, frequent scans and then finally undergo the oocyte retrieval process. However, the focus then shifts back to the recipient. This shift was recognised by the participants:

'You have got to value the egg donors as much as the people you are trying to help in the first place' (Debbie)

\section{Disclosure of biological motherhood}

One of the most important concerns post-donation was around the disclosure of the biological mother to the future child and their social circle. Each participant viewed it differently. Anne was unhappy when counsellors brought up the topic since she felt 
this was a personal matter and confessed that 'I did not want to know the reality'. Debbie and the recipient agreed that they would be open from the start and tell the child that 'she [her aunt] was the mother but he/she was not born from her eggs'. In contrast, Susan had serious concerns, because her sister was reticent towards disclosure:

'It's something that ought to be just known' [to prevent] 'possibilities of explosions later that we don't know about' [and] 'repercussions that could be passed on through generations'.

\section{Detachment from the egg and potential child}

A related concept was who had 'ownership' of a baby resulting from oocyte donation. Anne appeared to distance herself by describing the oocyte as an inanimate object:

'I flush them away once a month ... once they have left my body, they are not mine... I don't see an egg as a potential life'.

Debbie rationalised it as life beginning only when the egg is fertilised, so it is not hers as it would require fertilisation by her partner's sperm for it to be 'her' child

'I haven't carried the baby, it's not my baby... I know this child was not made with him, so therefore it's not our child.'

Susan, the only person whose egg donation led to a successful pregnancy did not find detachment so easy. Her words suggested she saw the child as hers, but being reared by her sister

'She would like to believe that he is her own child... urm ... and obviously she is bringing him up... It is hard seeing your own living [laughs] offspring sort of 
but that somebody else's in some ways... I am sure it's easier for my sister that it looks more like her husband [laughs] rather than her sister!

\section{Discussion}

This study aimed to identify motivations for oocyte donation in women who had donated to a family member by exploring their experiences and reflections on this process. A number of key interlinking themes were identified.

\section{Motivations for donation}

Research suggests that altruism shown by the oocyte donor is influenced by her personal relationship with the recipient, her own status as a mother and the wish to alleviate the emotional burden of infertility [13, 20-23]. These findings are consistent with the donors in this study who were willing to undergo the process only because they knew (and approved of) the recipients.

Oocyte donation is also said to contribute to the significance of motherhood by assisting others who are denied this option [24]. In these participants, the altruistic theme 'Giving the gift of motherhood' supported this idea and the concept of a woman's 'Right to motherhood'. In some societies, having children is widely assumed to be a natural and inevitable part of being a woman [25]. Motherhood can bring a sense of identity and status for some women [26]. It could be argued that that many women in industrialised societies have fewer children than they might wish due to financial considerations, the unequal division of domestic labour and impact on career [27]. Being an oocyte donor might satisfy a personal desire for 'motherhood by proxy' if perhaps the woman enjoyed being pregnant and found motherhood satisfying [28]. It is of note that the idea of surrogacy was raised by two participants. 
Anne raised it to suggest her commitment to her aunt's cause. Debbie's thoughts may have reflected a desire to be a mother again. For many women who have had children, whether or not to have another child is an ongoing dialogue until their fertility ends. It is suggested that woman's moral identity as ethical subjects are created in the donation process and that the stories these women tell pivot around identity construction [29]. The act of retelling their stories was significant because it afforded them a way to objectively manifest the subjective meanings they attributed to their gift-giving acts. The respect gained from others following oocyte donation was important to two of the women interviewed. In contrast, the sudden withdrawal of attention from themselves to the recipient was also noted. This situation has the potential to undermine the identity as a person of an altruistic, but significant individual.

Susan's narrative supports the alternative argument that donors may donate to be seen to conform to the 'caring' societal role assigned to women [16]. It is, however, difficult to distinguish between choice and conformity in practices of oocyte donation between close relatives. This may be called 'corporeal generosity', where the giving and receiving between selves and others is 'already in operation' as a fundamental element of their relationship occurring 'without any thought at all', which is supported by the 'unthinking' way in which Anne described her decision to donate [30]. Good family support and a stable relationship may be important factors in helping donors cope with the emotional aspects of donation. The two participants who were married emphasised the importance of their family's support for their decision. One study found that donors commonly had a strong belief that they were in control of their reproductive decision-making and also they would have the support of friends and 
family, if they decided to donate their oocytes [31]. However, it may also be that 'support' from a family can be a form of subtle social coercion, as in Susan's case the donation had the support of both parents and other siblings.

Susan donated to her sister but Anne and Debbie to their aunt. Because of the differences in the outcomes of the donation, this paper cannot throw light on whether or not cross-generational or same-generational donation has any implications towards the attitude or experience of the donors. However, it is possible that different generational power relationships may play a role in the nature of the 'obligation'. This area would benefit from further research.

Coping with the consequences of oocyte donation

Oocyte donation has the potential to be an emotionally and physically challenging procedure for which donors can be unprepared, especially in cases where the donation fails [23]. In some cases 'detachment' appears to be a coping strategy to avoid emotional attachment to a potential or actual child [11-14, 24, 32]. In this study Anne and Debbie employed this strategy, however, Susan whose donation led to a successful pregnancy found it difficult to dissociate herself from the child.

In cases of successful intra-familial donations, genetic relationship and the socially defined role of the donor in relation to the resulting child may pose additional challenges [12, 22, 33]. Susan was presented with an on-going intrapsychic dilemma in that any child born out of the donated oocytes was genetically linked to her but she would have no legal or social recognition as a mother. One of the most important concerns for both the donor and the recipient seems to be of disclosure of the biological mother to the future child and others in the social circle [11-12, 23, 31, 34]. 
A study exploring the concerns of anonymous donation recipient's feelings influencing their decision to enter into treatment demonstrated the contrasting attitude between women who were childless and women who had genetic children of their own. The participants with children expressed reservations and anxiety about how, and if, to disclose to the siblings who would have a different genetic make-up [35]. In this study Susan was in favour of full disclosure but it appeared the recipient was not. This might indicate that the attitudes towards disclosure before oocyte donation may change when a pregnancy is successful, leading to conflict within the relationship, although it is not known if the sister had already identified her reluctance prior to the donation.

\section{Study strengths and limitations}

To our knowledge, this is the first study to explore the motivations and experiences of 'known' donors using IPA. IPA enables an in-depth analysis of the experiences of these women to in a way previous survey research has not achieved. By design however, an IPA study focuses on a very small homogenous sample - here of white British women from one NHS service. Therefore these findings cannot be generalised to other populations. It is accepted that the sample size was small than what was aimed for but this was due to the fact that recruitment was limited by resources in terms of the first author's MSc research project and also willingness for participants coming forward to be interviewed. However, the sample size meets the requirement of IPA studies as prescribed by the methodologists [19]. In IPA 'less is more' and it is desirable to examine fewer cases in greater depth than in superficial and descriptive way. It is quoted that for a beginner conducting IPA studies for a Masters' level study a sample size of 3-6 participants is adequate [36]. A study of 
British women's attitudes towards oocyte donation demonstrated that ethnicity and religion are important determinants on the possibility of being donors [31]. Oocyte donation practice varies by country. In most Islamic countries oocyte donation is illegal [367]. In the USA donors are allowed monetary compensation for donation [378] whereas, in the UK the donor receives a 'reasonable reward' as recompense for their time [389].

The findings should be also be considered within the context that the interviewer was a male clinician working within the Reproductive medicine unit. This may have affected both the way the women told their story and the way the data were interpreted. To help address this, the analysis and interpretation was discussed in detail with the co-authors who were not involved in the service in any way.

\section{Future research recommendations}

The findings of this study points to a number of areas where further research is needed. As ethnicity and religion have implications for motivations, attitudes and experience of oocyte donation further research in a more diverse group is warranted. More qualitative research to investigate the motivation, attitudes and experience of different 'types' of donors are also indicated, e.g. with anonymous, patient and intergenerational donors. It is important to compare and contrast the views and experiences of these different groups to better understand the clinical population.

\section{Conclusion:}

This study demonstrates that motivations for oocyte donation can be complex, interwoven and sometimes paradoxical. Motivation can be influenced by the rewards of altruistic behaviour, the potential strengthening of the relationship between donor 
and recipient, but possibly also, a sense of obligation and societal demands resulting in subtle coercion and thus disempowerment. The study provides further insight to the motivations of known oocyte donors, the emotional consequences of this donation and the implications for familial relationships. Further qualitative research will provide a deeper understanding of these motivations, which in turn may change present practice and help in donor recruitment. The study highlights the importance of providing patient centred services oocyte donors as well as recipients. 


\section{Authors' roles}

SA co-designed and implemented the study design, conducted the interviews, analysed and interpreted the results and drafted the article.

LB and MT had overall responsibility for the post-graduate study of which this work was one part and were involved in co-design, analysis and interpretation of the data, critical appraisal of intellectual content and final approval.

Declaration of interests:

The authors report no conflicts of interest.

\section{Current knowledge on the subject:}

- Oocyte donation has the potential for significant psychological, physical and social impact for both the donor and recipient

- Oocyte donation between two people known to each other is assumed to have mainly altruistic motives

- Most primary research in this area has used survey methodology, which has not provided an in-depth exploration on the topic

\section{What this study adds:}

- Motivation is influenced by a combination of factors including the rewards of altruistic behaviour, the existence and potential strengthening of the relationship between donor and recipient, but possibly also, a sense of obligation and societal expectations 
- Oocyte donation can be variously viewed by donors as a unique way of reproductive empowerment or an example of acceding to subtle coercion and thus disempowerment

- The study highlights the clinical as well as ethical importance of providing individualised support services for oocyte donors and recipients

\section{References:}

1. CDC: 2013 ART Fertility Success Rates [Internet]. Centers for Disease Control and Prevention; [ cited 2015 Dec 25]. Available from: http://www.cdc.gov/art/reports/index.html

2. Jordan CB, Belar CD, Stan Williams R. Anonymous oocyte donation: a followup analysis of donors' experiences. J Psychosom Obstet Gynecol 2004;25:145-151.

3. Pennings G. Commentary on Craft and Thornhill:new ethical strategies to recruit gamete donors. Reprod Biomed Online 2007;10: 307-309

4. Human Fertilisation and Embryology Authority: (Disclosure of Donor Information) [Internet]. [ cited 2016 June 5]. Available from: http://www.hfea.gov.uk/5526.html

5. Human Fertilisation and Embryology Authority: (Disclosure of Donor Information) [Internet]. [ cited 2016 Apr 25]. Available from: http://www.hfea.gov.uk/docs/Egg and sperm donation in the UK 20122013.pdf 
6. Lessor R. All in the family: social processes in ovarian egg donation between sisters. Sociology of Health \& IIIness 1993;15 (3):393 - 413.

7. Sauer MV, Kavic SM. Oocyte and embryo donation: reviewing two decades of innovation and controversy. Reprod Biomed Online 2006;12(2):153-162.

8. Raoul-Duval A, Letur-Konirsch H, Frydman R. Anonymous oocyte donation: a psychological study of recipients, donors and children. Hum Reprod 1992;7: $51-54$.

9. Weil E, Cornet D, Sibony C, et al. Psychological aspects in anonymous and non-anonymous oocyte donation. Hum Reprod 1994;9:1344-1347.

10. Khamsi F, Endman MW, Lacanna IC et al. Some psychological aspects of oocyte donation from known donors on altruistic basis. Fertil Steril 1997;68:323-327.

11. Beatens P, Devroey P, Camus M, et al I. Counselling couples and donors for oocyte donation: the decision to use either known or anonymous oocytes. Hum Reprod 2000;15:476-484.

12. Fielding D, Handley S, Dugueno L, et al. Motivation, attitudes and experience of donation: a follow-up of women donating eggs in assisted conception treatment. J Community Appl Soc Psychol 1998;8(4):273-287.

13. Power M, Baber R, Abdalla $\mathrm{H}$, et al. A comparison of the attitudes of volunteer donors and infertile patient donors on an ovum donation programme. Hum Reprod 1990;5:352-355. 
14. Söderström-Antilla V. Follow-up study of Finnish volunteer oocyte donors concerning their attitudes to oocyte donation. Hum Reprod 1995;10:30733076.

15. Byrd LM, Sidebotham M, Lieberman B. Egg donation-the donor's views: an aid to future recruitment. Hum Fertil 2002;5:175-182.

16. Ulrich $M$, Weatherall A. Motherhood and Infertility: Viewing motherhood through the lens of infertility. Feminism \& Psychology 2000;10(3):323-336.

17. Hershberger P, Klock SC, Barnes RB. Disclosure decisions among pregnant women who received donor oocytes: a phenomenological study. Fertil Steril, 2007; 87: 288-296

18. Smith JA, Jarman M, Osborn M. Doing interpretative phenomenological analysis. In M. Murray \& K. Chamberlain (Eds.), Qualitative health psychology: Theories and methods. London: Sage 2003.

19. Smith JA, Osborn M. Interpretative phenomenological analysis. In JA Smith (Ed) Qualitative Psychology: A Practical Guide to Methods. London: Sage. 2008. ( $2^{\text {nd }}$ Ed). Pgs 53-80.

20. Kalfoglou AL, Gittelsohn J. A qualitative follow-up of women's experiences with oocyte donation. Hum Reprod. 2000;15:798-805.

21. Warren N, Blood J. Who donates? Why donate? An exploration of the characteristics and motivations of known egg donors: the Victoria, Australia experience. J Fertil Counselling 2003;10:20-24. 
22. Winter A, Daniluk JC. A gift from the heart: the experiences of women whose egg donation helped their sisters become mothers. J Couns Dev 2004;82:483495.

23. Yee S, Hitkari JA, Greenblatt EM. A follow-up study of women who donated oocytes to known recipients couples for altruistic reasons. Hum Reprod. $2007 ; 22: 2040-2050$.

24. Kirkman M. Egg and embryo donation and meaning of motherhood. Women Health 2003;38:1-18.

25. Rowland R. Living laboratories: women and reproductive technology. London:Cedar 1992.

26. Morell CM. Unwomanly Conduct: The challenges of intentional childlessness. London: Routledge. 1994.

27. Currie D. 'Rethinking what to do and how we do it: A study of reproductive decisions'. Canadian Review of Sociology and Anthropology. 1988;25 (2):231253.

28. Jadva V, Murray C, Lycett E, et al. Surrogacy: the experiences of surrogate mothers. Hum Reprod. 2003;18(10):2196-2204.29.

29. Shaw R. The gift-exchange and reciprocity of women in donor-assisted conception. Sociol Rev 2007;55 (2):293-310.

30. Diprose R. Corporeal generosity: On giving with Nietzsche, Merleau-Ponty, and Levinas. United States of America: State University of New York Press 2002. 
31. Purewal S, Van den Akker OB. British women's attitudes towards oocyte donation: ethnic differences and altruism. Patient Educ Couns 2006;64(13):43-49.

32. Frith L, Blyth E, Farrand A. UK gamete donors' reflections on the removal of anonymity: implications for recruitment. Hum Reprod. 2007;2:1675-1680.

33. Saunders DM, Garner F. Oocyte donation using 'known' donors: it may seem the convenient answer but who pays? Hum Reprod 1996;11:2356-2357.

34. Craft I, Flyckt S, Heeley G, et al. Will removal of anonymity influence the recruitment of egg donors? A survey of past donors and recipients. Reprod Biomed Online 2005;10:325-329.

35. Stuart-Smith SJ, Smith JA, Scott EJ. Treatment decision making in anonymous donor egg in-vitro fertilisation: A qualitative study of childless women and women with genetically related children. Human Fertility 2011;14(2):97-105.

36. Hefferon K, Gil-Rodriguez E. Interpretative phenomenological analysis. The Psychologist. 2011;24:756-759.

367. Husain FA. Reproductive issues from the Islamic perspective. Human Fertility. 2000; 3(2): $124-128$.

37․․ American Society for Reproductive Medicine (ASRM). Financial compensation of oocyte donors. Fertil Steril 2007; 88: 305-309. 38.

389. Human Fertilisation and Embryology Authority: (Payment for donors) [Internet]. [ cited 2016 May 25]. Available from: http://www.hfea.gov.uk/7091.html 